\title{
A Step Toward Optimizing Regenerative Medicine Principle to Combat COVID-19
}

\author{
Shilpa Sharma ${ }^{1, \odot}$ Madhan Jeyaraman ${ }^{2, \odot}$ Sathish Muthu ${ }^{3, \odot} \quad$ Talagavadi Channaiah Anudeep ${ }^{4, \odot}$ \\ Naveen Jeyaraman ${ }^{5, \odot}$ Ajay Satish Shringeri ${ }^{6, \odot} \quad$ Vinodh Kumar $^{7, \odot}$ Rajeswari Somasundaram ${ }^{8, \odot}$ \\ Rashmi Jain ${ }^{9, \odot ~ S a u r a b h ~ K u m a r ~ J h a ~}{ }^{10, \odot}$
}

${ }^{1}$ Department of Paediatric Surgery, All India Institute of Medical Sciences, New Delhi, India

2Department of Orthopaedics, School of Medical Sciences and Research, Sharda University, Greater Noida, Uttar Pradesh, India ${ }^{3}$ Department of Orthopaedics, Government Medical College and Hospital, Dindigul, Tamil Nadu, India

${ }^{4}$ Department of Plastic Surgery, Topiwala National Medical College and BYL Nair Ch. Hospital, Mumbai, Maharashtra, India

${ }^{5}$ Department of Orthopaedics, Kasturba Medical College, MAHE University, Manipal, Karnataka, India

${ }^{6}$ Department of Orthopedics, Sri Devaraj URS Medical College,

Kolar, Karnataka, India

${ }^{7}$ Biocon Biologics, Chennai, Tamil Nadu, India

${ }^{8}$ Department of Microbiology, PSG BioNEST, PSG TECH, Coimbatore, Tamil Nadu, India

${ }^{9}$ School of Medical Sciences and Research, Sharda University,

Greater Noida, Uttar Pradesh, India

${ }^{10}$ Department of Biotechnology, School of Engineering and

Technology, Sharda University, Greater Noida, Uttar Pradesh, India

\author{
Address for correspondence Madhan Jeyaraman, MS (Ortho), \\ Department of Orthopedics, School of Medical Sciences and \\ Research, Sharda University, Greater Noida 201306, Uttar Pradesh, \\ India (e-mail: madhanjeyaraman@gmail.com).
}

\begin{abstract}
Keywords

- COVID-19

- mesenchymal stem cells

- convalescent plasma

- pandemic

Drugs are currently not licensed in specific to pulverize COVID-19. On an emergency basis, vaccines were approved to prevent the further spread of COVID-19. This serves as a potential background for considering the optimization of biologics. In this context, evidence on convalescent plasma and stem cells has shown a beneficial role. Here, we have considered this as plausible therapy, and further hypothesize that their cocktails will synergistically boost the immunogenicity to relegate COVID-19. This warrants a large volume clinical trial on an emergent basis, because the sooner we establish a safe and effective cure, the better.
\end{abstract}

\section{Introduction}

The world is currently jeopardized by the pandemic Coronavirus infection, called COVID-19. It has spread across the world rapidly, resulting in the World Health Organization
(WHO) announcing it as a pandemic on March 11, 2020. This pandemic of COVID-19 has not only brought life to a standstill but has also challenged the public health facility, advancing medical sciences and technologies. The contagion is transmitted from person to person either by direct contact or published online June 21, 2021
DOI https://doi.org/ $10.1055 / \mathrm{s}-0041-1731597$ ISSN $0379-038 \mathrm{X}$ (c) 2021. National Academy of Medical Sciences (India).

This is an open access article published by Thieme under the terms of the Creative Commons Attribution-NonDerivative-NonCommercial-License, permitting copying and reproduction so long as the original work is given appropriate credit. Contents may not be used for commercial purposes, or adapted, remixed, transformed or built upon. (https://creativecommons.org/licenses/by-nc-nd/4.0/).

Thieme Medical and Scientific Publishers Pvt. Ltd. A-12, 2nd Floor, Sector 2, Noida-201301 UP, India 
indirect contact. Currently, there are 116,849,611 confirmed cases with 2,593,230 deaths (as of March 8, 2021). ${ }^{1}$ People with low immunity, old age, and medical comorbidity, especially related to lungs, are more prone to COVID-19 disease. The incidence and mortality are varying across countries and territories. ${ }^{1}$ The clinical learning from previous episodes of Coronavirus outbreaks (SARS-CoV- 1 and MERS-CoV) and other episodes of viral etiology has preluded subsets of drugs as empirical therapy. ${ }^{2}$ These subsets include protease inhibitors (ritonavir; lopinavir), aminoquinolines (chloroquine and hydroxychloroquine), nucleotide analog (remdesivir) and pyrazine carboxamide-derived prodrug (favipiravir) along with adjuncts including azithromycin, corticosteroids and interleukin-6 (IL-6) inhibitors, which have been subjected to various clinical trials across various countries. ${ }^{2,3}$ As of now, over 90 countries are working together under the WHO's launched mega trial "Solidarity" for finding the effectiveness of four subsets of drugs (with selection based on evidence from laboratory, animal, and clinical studies)-remdesivir; lopinavir/ritonavir; lopinavir/ritonavir with interferon $\beta 1 \mathrm{a}$; and chloroquine or hydroxychloroquine. ${ }^{4-6}$ To date, in India, vaccines like covishield and covaxin are available in the market to prevent COVID-19 infection. ${ }^{7}$ This background draws potential attention for optimizing the principles of regenerative medicine to combat the severe acute respiratory syndrome Coronavirus-2 (SARS-CoV-2) pandemic. Evidence has shown its beneficial role. This article aims to outline the principle mechanism of novel therapeutics (mesenchymal stem cells [MSCs] and convalescent plasma [CP] and cocktails), channelized for the relegation of COVID-19, as shown in - Fig. 1.

\section{Convalescent Plasma Therapy for SARS-CoV-2}

Convalescent plasma (CP) therapy, classic adaptive immunotherapy, has been under the radar for preventing and treating a number of infectious etiologies for more than a century. ${ }^{8-10}$ One of the effective passive therapeutic approaches during an outbreak of any infectious disease is the passive antibody therapy from convalescent patient serum who has recovered from the infection. The viral neutralizing antibodies, as a subset, subjugate viral infectivity. By binding to the surface epitopes present over viral particles, they block the entry of the virus into the cell. ${ }^{11}$ Protective activities are elicited by three key ways which prevent the attachment of the virion to its receptors on the target cells, resulting in aggregates of viral particles. Further, the constant (C) region of the antibody-mediated opsonization or complement activation sets the way to lyse SARS-CoV-2. ${ }^{2}$

$\mathrm{CP}$, as a therapeutic development, is the need of the hour, as it is not only a prerequisite in controlling this prevailing pandemic but also a plausible preventive strategy to counteract the reemergence of the SARS-CoV-2. ${ }^{13,14}$ The development of CP therapy efforts will be an area of enormous research in the coming years. Currently, several strategies such as antiviral therapeutics and host-targeting agents in the treatment of SARS-CoV-2 are being used. Compared to these therapeutic modalities, CP therapy appears to be more specific for immune development and is responsible for a high recovery rate among infected patients. ${ }^{15-17}$ Understanding the mechanism of action of CP therapy may layout an equivocal reflection for the development of immunotherapy and passive therapy for SARS-CoV-2 expeditiously (as shown in -Fig. 2). ${ }^{14,15}$

To date, it has been reported that $\mathrm{CP}$ therapy for both SARS-CoV and MERS-CoV has resulted in effective recovery of the infected individuals in previous outbreaks and epidemics. ${ }^{16-18}$ Also, it is to be noted that the effect of antibody immune response to protection against SARS-CoV's pulmonary pathology is seemingly controversial in some cases and thereby calls for cautious addressal by considering humoral and cellular immune responses of SARS-CoV-2, following the development of this antiviral immunotherapy. ${ }^{19}$ This type

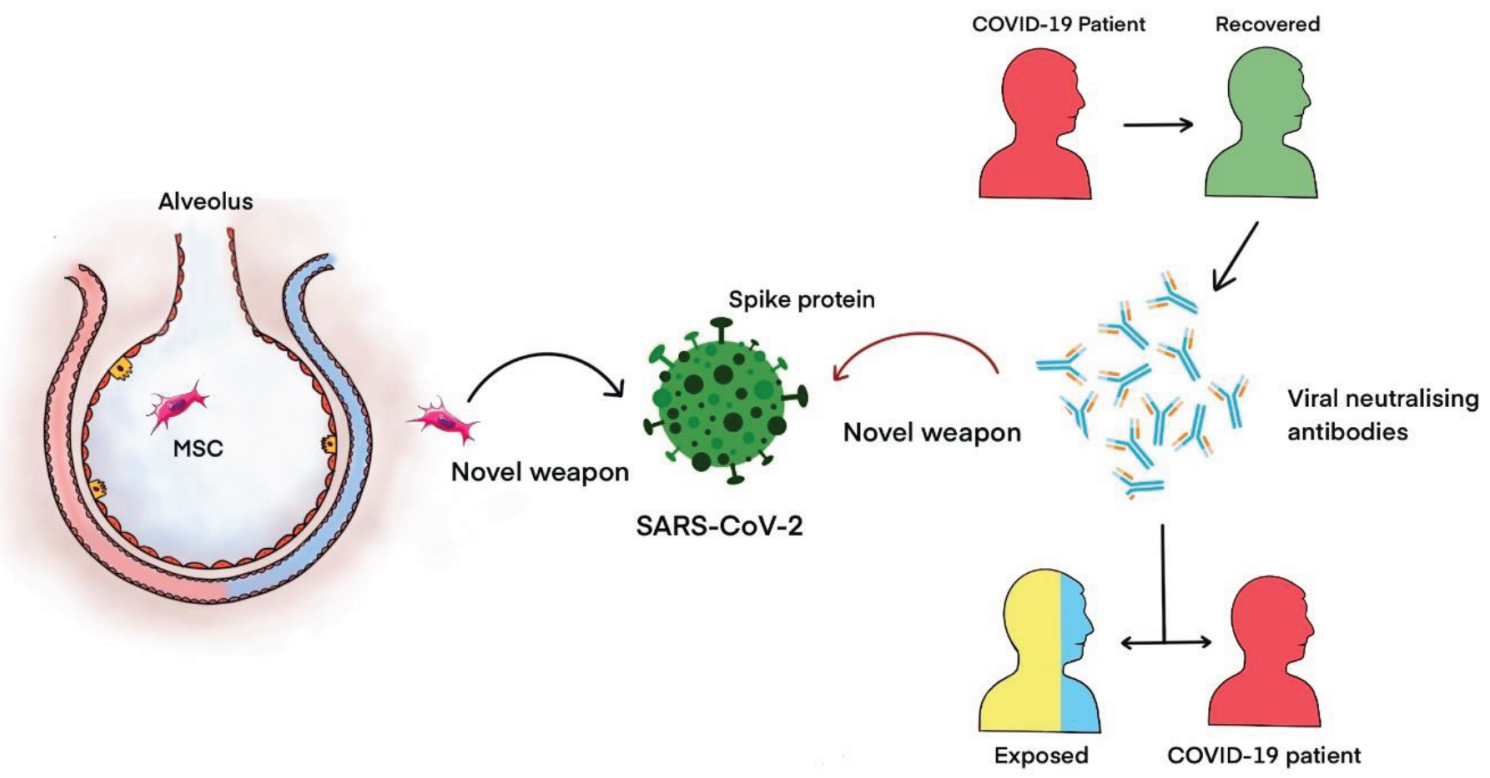

Fig. 1 Optimization of regenerative medicine principles in nCOVID-19. 


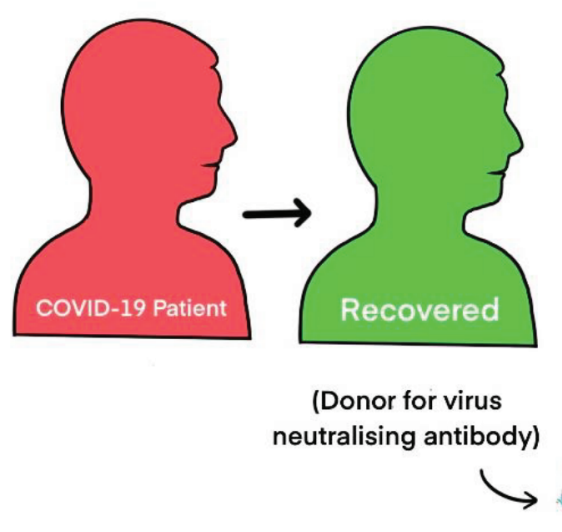

Fig. 2 Convalescent plasma (CP) therapy in nCOVID-19.
(A)

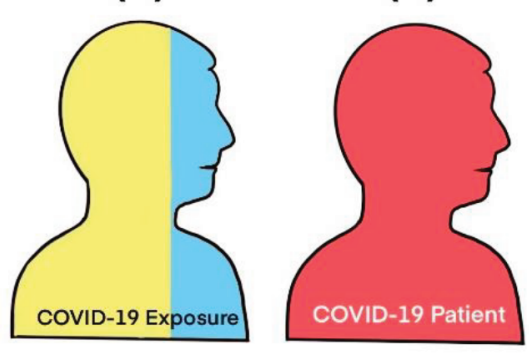

(Recipients for convalescent plasma)

(A) As prophylaxis

(B) As therapy of passive therapy is simple but serves as a very potential effective tool for developing immediate immune responses under critical conditions. In the current COVID-19 pandemic, the patients with resolved SARS-CoV-2 infection will have significant serum antibody immune response $(\operatorname{IgG})$ to different viral epitopes of the SARS-CoV-2 whole virus particle, and some of these developed antibody responses in the host system will likely be neutralizing the viruses, significantly preventing the chances of getting reinfection because of high level of antibody titers produced by their host immune system against the SARS-CoV-2 viruses earlier. ${ }^{13,20}$

Plasma transfusion has been widely used in many other medical conditions in general; thus, it does not require any newer science or technology or any medical approvals for its incorporation into the treatment regimen. Since the SARS-CoV-2 pandemic health crisis continues to be a challenge, the patients who survived this SARS-CoV-2 infection can be the effective serum donors to make antisera for treating SARS-CoV-2 patients, thereby leading to the development of storage of significant antisera stocks for treating infected patients. ${ }^{9,21}$ The potency of antiviral effects with convalescent patients' sera, moreover, would have higher significant variability, making it less ideal.

Despite the initial treatment measures taken with regard to improvement of oral antiviral drugs and steroidal agents, the chances of patients experiencing an exacerbation of this viral infection have been noticed in the second week of treatment, and after aggressive immunomodulatory therapy, the patients were found to record improvements on their way to complete recovery from the infection effectively. ${ }^{22,23}$ This was also because of the persistence of lymphopenia, which may be an indication of persistent disease activity. ${ }^{23,24}$ Hence, one of the best ways to reduce the viral load in the host system is through immunoglobulin administration against the viruses, and it is reported in previous studies with SARS-CoV that the fever decreases upon administration of CP of specific immunoglobulins for the prevention of infection rather than treatment of viruses. ${ }^{25}$

Production of such $\mathrm{CP}$ is dependent completely on the presence and willingness of the SARS-CoV-2 survivor to provide plasma for treating other infected patients. Also, the nature of monoclonal antibody cocktails is highly advantageous in defined doses that can be administered to the infected patients for the purposes of recovery. Large-scale production can be relatively easier, and polyclonal antibodies (serum) would contain several non-neutralizing and neutralizing antibodies that would greatly reduce the potential for escape mutants. ${ }^{26,27}$

A study by Duan et al, in 2020, showed that CP therapy was well-tolerated by 10 severely-ill patients (confirmed by real-time viral RNA test) and further accounted for potential improvisation in clinical outcome by neutralizing viremia in these patients. These patients were enrolled prospectively and were administered a single dose of $200 \mathrm{~mL}$ of $\mathrm{CP}$ procured from recently recovered donors having neutralizing antibody titers above 1:640 along with maximal supportive care and antiviral agents. ${ }^{28}$ Safety of CP transfusion was the primary end-point, while improvised symptomatology and laboratory parameters within 3 days following CP transfusion served as secondary end-points. However, it addressed the need for further investigation in controlled trials at the larger level for optimizing the dose, timing, and clinical benefit. ${ }^{28}$ The dire lack of specific antiviral medicine fuels the need for an alternative modality for treating COVID-19 infection, especially for severe COVID-19 affected patients. ${ }^{16,23}$

Services under the branch of transfusion medicine should now certainly put forth convalescent patient sera as the right option for treating infected patients, which would lead to significant recovery. Although the mechanism of action and the timing of CP in SARS-CoV-2 has to be studied further, immunotherapeutic treatment with $\mathrm{CP}$ is a promising option as a life-saving treatment for SARS-CoV-2 infected patients with potential benefits. ${ }^{15,29}$

\section{Mesenchymal Stem Cells Therapy for COVID-19}

The research analysis on the molecular pathogenesis has highlighted how angiotensin-converting enzyme-2 (ACE2) receptors facilitate the viral entry into the human host and 
further shed infectivity. To date, no specific effective treatment has been approved for COVID-19. Avoidance is the principal strategy of deterrence. The search is on for a definitive treatment against this contagion by numerous collaborative bodies around the globe.

Advancing molecular and regenerative medicine has led to the emergence of biologically active cells such as stem cells, bioactive materials, and growth factors in the healing process and tissue regeneration. The basis of regenerative medicine is as follows:

a. Provision of a matrix, composed of ground substance and scaffold, wherein the stem cells form the targeted tissue of interest.

b. A change in the microenvironment around the cells to direct the healing of damaged tissues.

c. Utilizing potent substances like growth factors for inducing the tissue of interest.

d. Use of stem cells as biologically potent cells to produce the tissue of interest. ${ }^{30-32}$

Cellular therapy offers a revolutionary cascade of natural healing. ${ }^{33,34}$ Administration of stem cells aids in escalating treatment and leads to functional recovery from diseases. Stem cell promotes biological healing of disease. Therefore, MSCs serve as the perfect cell-based, tissue-regenerative modality for treating disorders under a minimally invasive environment and without any significant morbidity. ${ }^{35,36}$ The field of cellular therapy further induces cellular proliferation, differentiation, characterization, regeneration, and rejuvenation of degenerated tissue to attain naïve homeostasis. ${ }^{37-39}$

Among cellular therapy, various researchers have reported that MSCs are ubiquitous in nature. MSC is blessed with unique self-renewal property (obligatory asymmetric or stochastic replication), plasticity, multilineage differentiation potential, homing ability, immunoregulatory nature, and anti-inflammatory effects..$^{40,41}$ MSCs are readily accessible and expandable in vitro with exceptional genomic stability. ${ }^{34,42,43}$ However, ethical concerns pertaining to MSCs remain debatable. ${ }^{44-46}$

MSCs are found in bone marrow, cord cells, adipose tissue, amniotic fluid, and molar teeth. ${ }^{47,48}$ The choice of source of MSCs is also debatable. ${ }^{43,49}$ Bone marrow-derived MSCs (BM-MSCs) can be derived from the iliac crest and should be subjected to centrifugation (3200 rpm for 15 minutes) to concentrate MSCs. ${ }^{40,50}$ Autologous BM-MSCs avoid immunogenic reactions once administered. ${ }^{51}$ Adipose-derived mesenchymal stem cells (AD-MSCs) are found in abundance in the human body, which can be accessed easily. However, the process of concentrating stem cells warrants complex processing to obtain adipose tissue-derived stromal vascular fraction (SVF). SVF is an aqueous fraction with a combination of adipose-derived stem cells, endothelial precursor cells, endothelial cells, macrophages, smooth muscle cells, lymphocytes, pericytes, and preadipocytes. ${ }^{52-54}$ The stem cell activity of adipose-derived SVF is three times higher than BM-MSCs. ${ }^{55,56}$ Umbilical cord-derived mesenchymal stem cells (UC-MSCs) are allogenic. Combating immunological reaction with allogenic UC-MSCs warrants lyophilization of
UC-MSCs, which is a complex procedure. ${ }^{57,58}$ They are delivered to produce the target action via direct delivery (aspirated stem cells are directed toward the injury site) and cell-based delivery (isolation, culture, and differentiation in media to exponentially increase their numbers before application at the injury site). ${ }^{40,59,60}$

MSCs attenuate the generation of Th1, Th2, and Th17 cells by modulating the antigen-presenting function of dendritic cells in a cytokine-dependent manner. ${ }^{61-63}$ MSCs render dendritic cells ineffective due to the decreased expression of the major histocompatibility complex (MHC) and costimulatory molecules. Thus, MSCs modulate immune-stimulatory mechanisms in the injured lung parenchyma. ${ }^{64-66}$

MSCs curb microbial agents by downregulating proinflammatory molecules and upregulating anti-inflammatory molecules. There is increased phagocytosis and upregulation of indoleamine 2,3 dioxygenase (IDO) and IL-17, which renders MSCs with antimicrobial effects. ${ }^{67-69}$ MSCs attack intracellular targets and inhibit the process of transcription, translation, and posttranslational modifications of viral proteins. Hence, MSCs initiate the hyperimmune response to microbial agents (as shown in - Fig. 3). ${ }^{70}$

MSC-derived exosomes act as a cell-free targeted therapy to exert the therapeutic action. There are eight clinical trials registered as of March 8, 2021. MSC-derived exosome consists of both extracellular vesicles and several soluble proteins, cytokines, chemokines, and growth factors. ${ }^{71}$ This exosome can interact with the target cells and modify the recipient cell's fate by endogenous stem cell activation, apoptosis suppression, regulation of the inflammatory response, fibrosis reduction, and mediation of chemoattraction. ${ }^{72,73}$ The immunomodulatory cargo of MSCs exosomes combined with the antiviral drugs make them a novel intervention tool for the treatment of the disease. ${ }^{74}$ Remdesivir antiviral drug, which is prescribed for the treatment of patients with COVID-19, can be loaded into the exosome. ${ }^{75,76}$ However, in the case of COVID-19, more scrutiny is essential to have a full

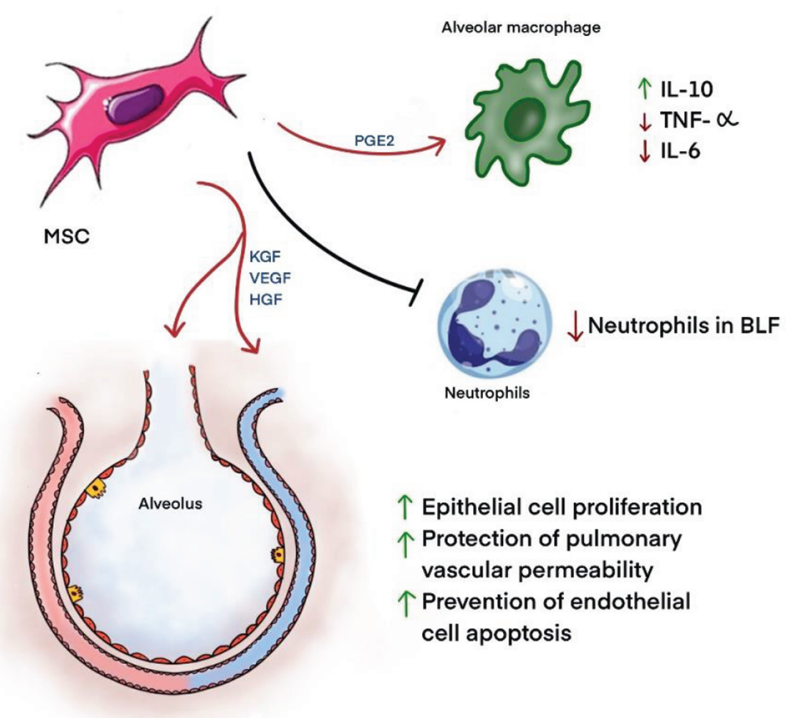

Fig. 3 Effects of mesenchymal stem cells (MSCs) in nCOVID-19. 
understanding of their safety, specificity, proficiency, and delivery mechanisms of antiretroviral drugs to target tissues.

\section{Route of Administration}

MSCs, once administered through the intravenous route, enter the systemic circulation to reach pulmonary circulation and settle in the injured pulmonary parenchyma. Once it reaches the site of action, MSCs are differentiated into type 2 alveolar epithelium. Researchers, in pilot studies, have administered UC-MSCs through an intravenous (IV) route. ${ }^{77,78}$ Tzouvelekis et al documented excellent pulmonary function with three endobronchial infusions of autologous adipose-derived stem cells at the rate of 0.5 million cells per $\mathrm{kg}$ of body weight per infusion in patients with idiopathic pulmonary fibrosis without any side effects. ${ }^{79,80}$ Endobronchial administration entails the risk of aerosolization. ${ }^{81,82}$ The efficacy of IV or endobronchial route administration have to be validated and documented.

SARS-CoV-2 uses ACE-2 receptors for entry, and TMPRSS-2 serine protease aids in S protein priming which spreads the infection to the host. ${ }^{83-85}$ These receptors show a wide range of expression not only in pulmonary parenchyma but also in cardiac, hepatic, and renal tissues which lead to dyspnea, systemic inflammatory response syndrome (SIRS), multiple organ dysfunction syndrome (MODS), and death in COVID-19 positive patients. ${ }^{41,85,86}$ The intervention with MSCs in COVID-19 patients has immunomodulatory effects and simulates differentiation abilities. In COVID-19 patients, IV administration of MSCs leads to the upregulation of neutralizing chemokines IL-10 and IL-17, and rejuvenates and regenerates the repaired parenchymatous pulmonary tissue through neoangiogenesis. ${ }^{87-89}$ Hence, the patient will have an improved pulmonary function, compliance, and recovery from COVID-19 pneumonia.

There are 72 trials registered on clinicaltrials.gov to elucidate the role of MSCs in COVID-19, of which 32 are recruiting, 18 are not recruiting, 3 are enrolling by invitation, 8 are active and not recruiting, 2 studies are withdrawn (NCT04293692 and NCT04341610), the status of one study is unknown, and 8 studies are completed as on March 8, 2021.90

A few researchers have performed a pilot study on MSCs to combat COVID-19 pneumonia. Leng et al used $10^{6}$ clinical-grade MSCs per kilogram of weight, which was given as an IV dose to all the 7 patients and proved clinical improvement of the patients and concluded MSCs are not infected by SARS-CoV-2. ${ }^{91}$ Liang et al IV infused three doses of $5 \times 10^{7}$ hUCMSC in a critically ill 65 -year-old patient, which significantly improved the patient's condition without any side effects. ${ }^{92}$ As 5 clinical trials are completed, MSCs pave a ray of hope in COVID-19, because of its regenerative and immunomodulatory potential. The results of the completed studies are tabulated in - Table $\mathbf{1}$.

\section{Ethical Concern with MSCs}

The Food and Drug Administration (FDA) guidelines defined cultured cells as "minimally" and "more than minimally" manipulated, which describe procedures "that might alter the biological features of the cells." ${ }^{40,93}$ The criteria of minimal manipulation conditions have not been precisely framed and documented for the collection and isolation of MSCs. Various studies concluded inadequate information regarding the cell culture protocols due to the use of supplemented cell culture media, enzymatic treatment, and long-term cell expansion that are known to change the quality of MSCs. ${ }^{43,94} \mathrm{To}$ reiterate, protocols for isolation and culturing as per Good Manufacturing Practice (GMP) requirements still need optimal validation.

Human cellular and tissue-based therapies or products (HCT/Ps) are regulated by FDA under Section 351 and Section $361 .{ }^{95}$ FDA emphasizes on halting of communicable diseases transmission between donor and recipient to improve the manufacturing units which, in turn, reduce the risk of contamination and demonstrate effectiveness and safety of the processed cells for use.

FDA defines minimal manipulation of cells/tissues as the processing of cells/tissues, which does not alter biological characteristics of cells/tissues of interest. ${ }^{96-99}$ Under part 1271 and section 361, FDA laid the criteria for cellular therapy as minimally manipulated, involves homologous use, avoids combination of cells and tissues with any other substances, causes no systemic effect, is independent of cellular metabolism, and utilized for autologous and allogeneic use in first or second-degree relatives. ${ }^{40}$

\section{Plausible Combination of CP + MSC for COVID-19}

There are no trials conducted except a case report to elucidate the combined efficacy of MSCs and CP when administered together. ${ }^{100}$ MSCs are bestowed with homing ability, immune-regulatory nature, anti-inflammatory effects, multilineage differentiation potential, and lack of ACE2 and TMPRSS2 receptors. ${ }^{41,88,89}$ MSCs are innately immune to SARS-CoV-2 infection as they lack key entry points. $^{70,101}$

Immunomodulatory and regenerative potential of MSCs promote repair, regeneration, and rejuvenation of pulmonary parenchymal cells, and also resist necroapoptosis and fibrosis of damaged pulmonary parenchymal tissues, which make MSCs a novel therapeutic option in the inflammatory or late stage of the disease. ${ }^{102-104}$

On the other hand, $\mathrm{CP}$, being passive immunotherapy, is more effective as prophylaxis than as a treatment. When used as a therapeutic agent, it has to be administered in the early phase of the disease, just after the onset of symptoms. This variable efficacy concerning time has not been lucidly understood, butitmay be because of the smaller size of viralinoculum in the early stage of the disease, which is easy to neutralize. ${ }^{105}$ Antibodies alter the inflammatory response and the same can be more easily achieved during the initial immune response, that is, during the asymptomatic stage. ${ }^{106}$ As an example, to highlight the efficacy concerning time, passive antibody therapy for pneumococcal pneumonia was most effective 
Optimizing Regenerative Medicine Principle to Combat COVID-19 Sharma et al. 207

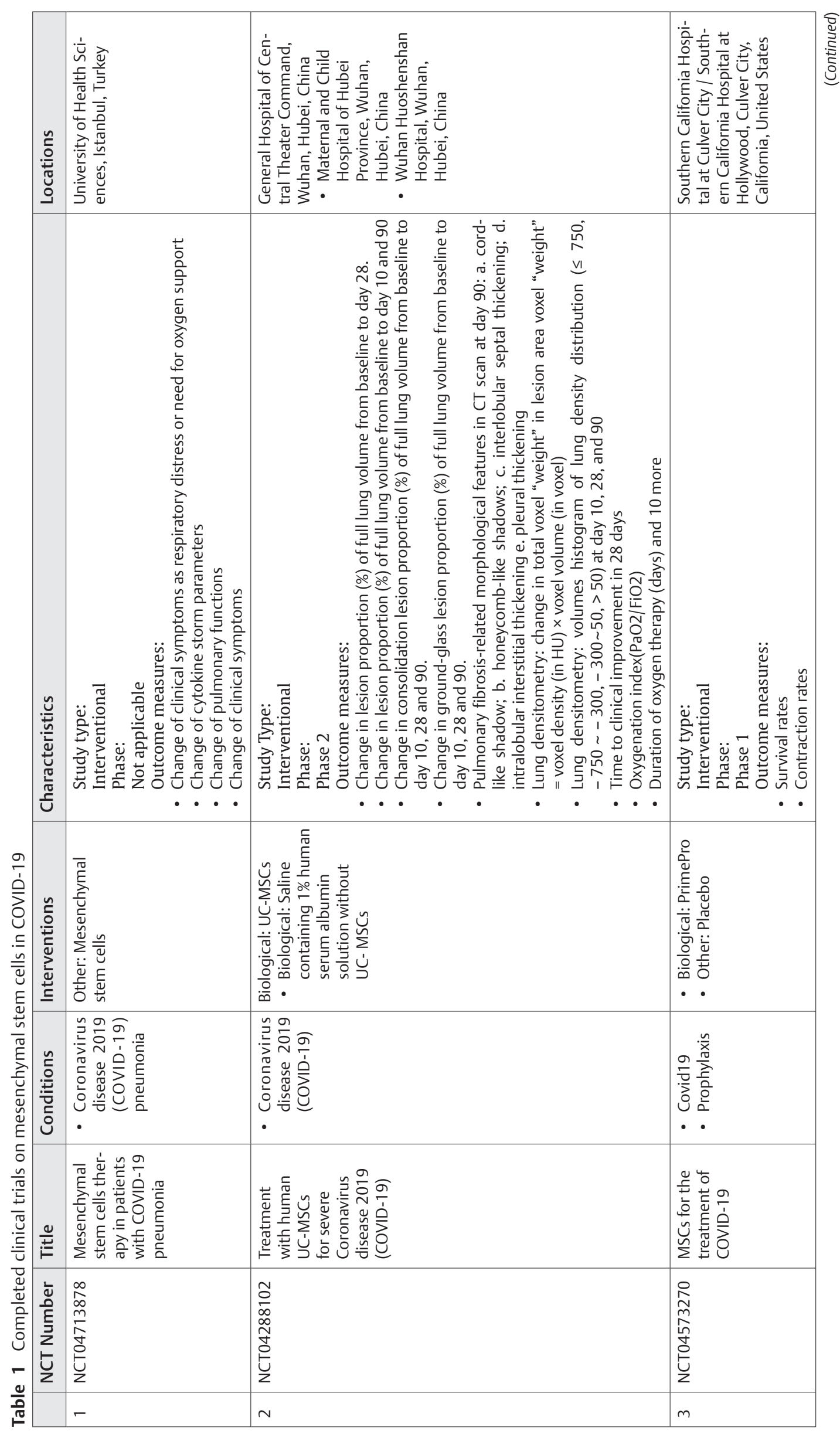




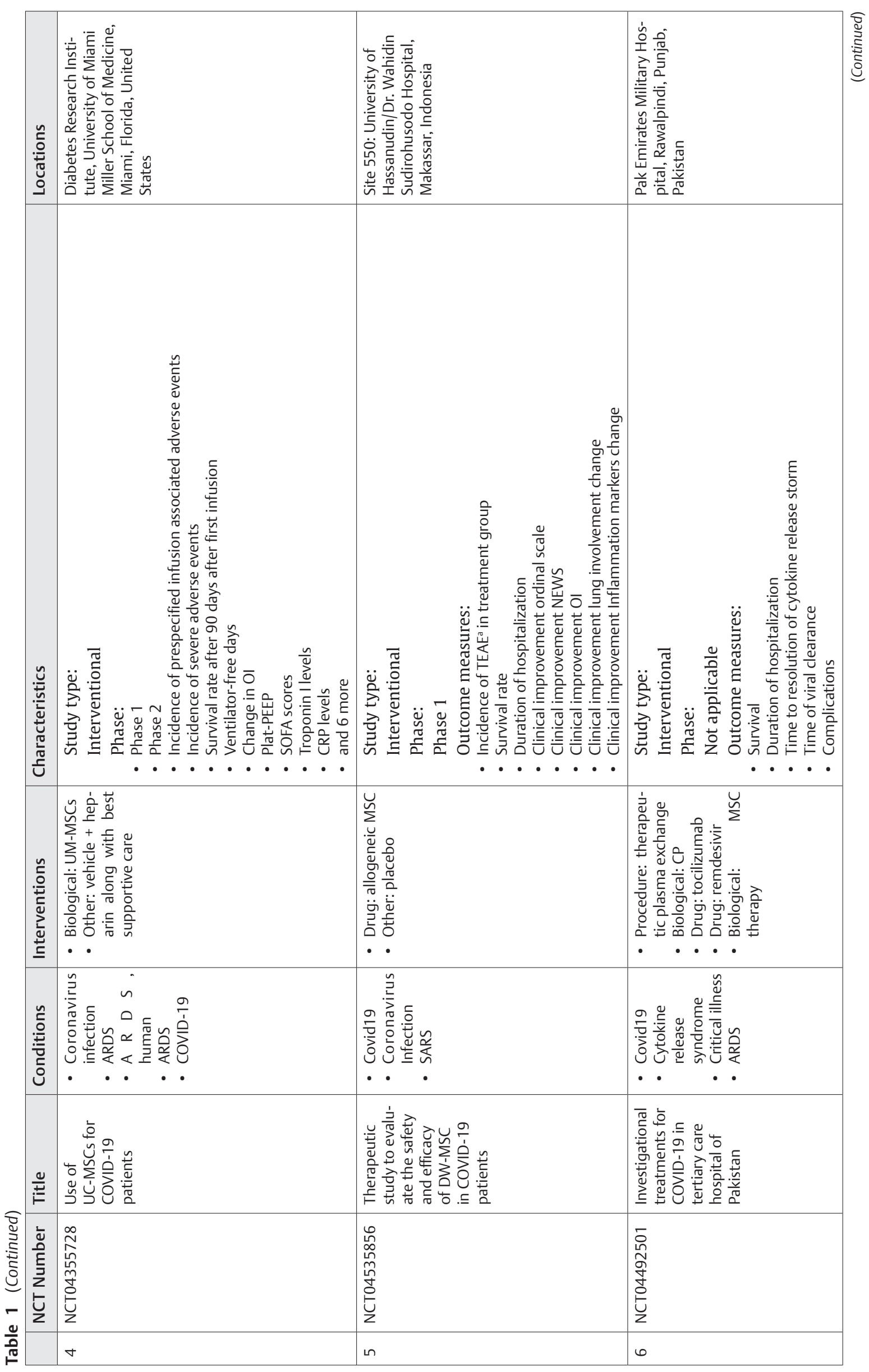


Optimizing Regenerative Medicine Principle to Combat COVID-19 Sharma et al. 209

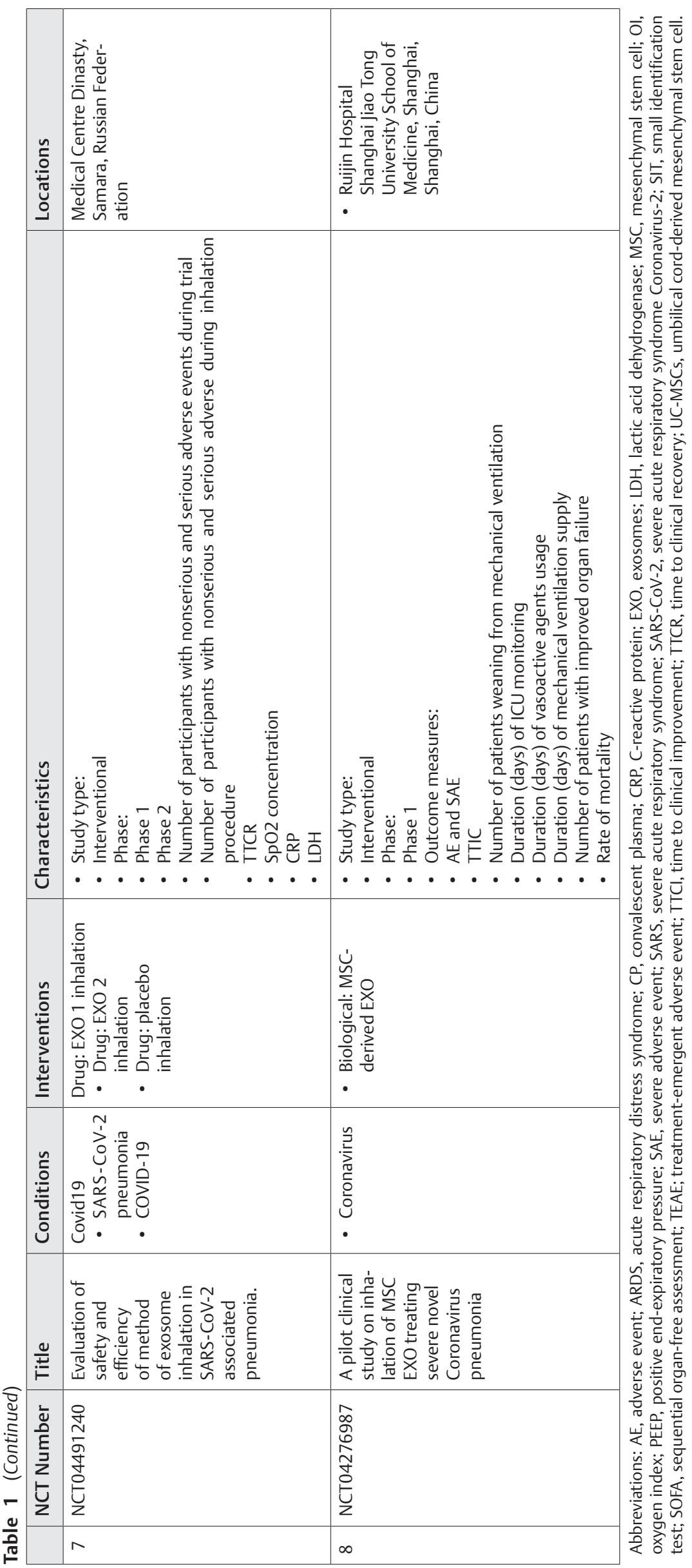

Annals of the National Academy of Medical Sciences (India) Vol. 57 No. 4/2021 (c) 2021. National Academy of Medical Sciences (India). 


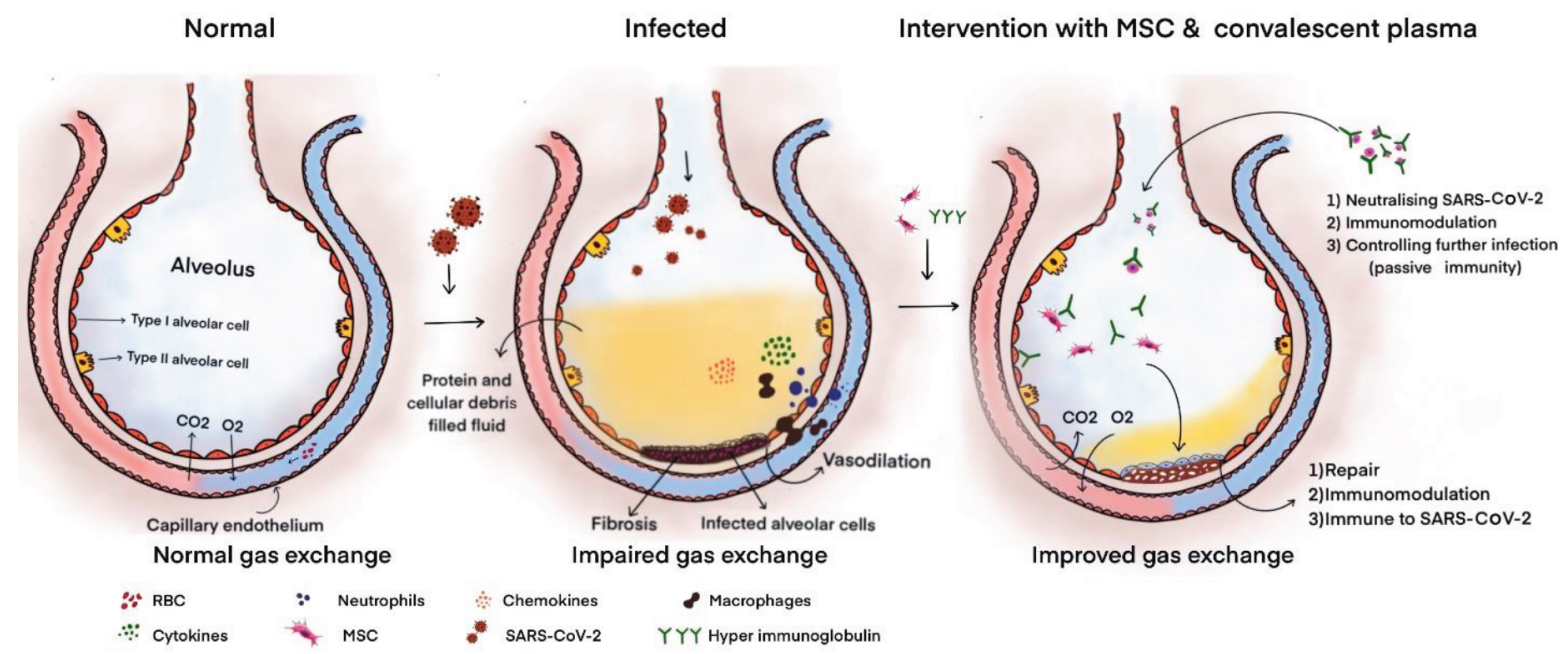

Fig. 4 Optimization of combination treatment (convalescent plasma [CP] + mesenchymal stem cells [MSCs]) in nCOVID-19.

when administered shortly after the onset of symptoms; on the other hand, no benefit was reported when it was administered 3 days after the onset. ${ }^{107}$ Also, treating severe acute respiratory infection revealed that the early use of $\mathrm{CP}$ after the onset of symptoms is associated with a reduced death rate. ${ }^{28}$

Peng et al instituted $\mathrm{CP}$ therapy twice with immunoglobulin-G (IgG) antibody titer greater than $1: 160$ for an acute respiratory distress syndrome (ARDS) case due to SARS-CoV-2. Following the immediate next day, they observed an increase in absolute lymphocyte count, which returned to normal on the fourth day. Then UC-MSCs of $6.5 \times 10^{7}$ cells were IV infused at a rate of approximately 40 to $55 \mathrm{drops} / \mathrm{min}$ for approximately 30 to 40 minutes, once every 3 days, three times. No adverse effects were observed in the patient. With 7 days of the treatment, CT chest showed absorption of bilateral chest infiltrates. The patient was reviewed after a week and showed complete resolution of symptoms. Early application of CP therapy can inhibit a large number of virus replication, promote virus excretion, significantly shorten hospital stay, improve prognosis, and reduce mortality, whereas MSCs improve the pulmonary microenvironment, promote the endogenous repair of the host, and repair pulmonary damage caused by inflammation, thereby restoring the lung diffusion function and improve pulmonary function and compliance. MSCs play a role in antiviral pneumonia by including paracrine factors, exocrine vesicles, and mitochondrial transfer, which can inhibit the inflammatory response and avoid cytokine storms; it can also reduce and clear alveolar effusion to reduce pulmonary edema. ${ }^{100}$

It is very much clear that $\mathrm{CP}$ is more effective in the early phase of the disease, whereas MSCs act in the late inflammatory stage of the disease, which can pave the way to combine these two modalities. MSCs + CP combination therapy has every potential to synergistically exert its therapeutic action against SARS-CoV-2 (as shown in - Fig. 4). Well-structured randomized controlled trials are essential to confer the efficacy and safety of this combination therapy.

\section{Conclusion}

The world is withstanding a greater loss of human lives and economy from the outbreak of SARS-CoV-2 contagiously. Presently, we are battling this situation with no specifically approved armors (drugs and biologics), quelling this contagion. This impelled the consideration of divergent modalities, which stemmed from the core principles of regenerative medicine. The therapeutic characterization of $\mathrm{CP}$ therapy and MSC therapy has been explicitly discussed above. Indeed, these therapies express the potential to relegate COVID-19. However, to elucidate the safety and effectiveness of this treatment modality, a large number of clinical trials are warranted. These may be tried in isolation or in a synergistic manner or one after the other in cases of poor response to one. The pandemic has paved the way for innovating, and experimenting with novel ways, on account of the emergent need to search for a cure. However, as time is a big constraint, and since this life-threatening pandemic has spread like wildfire across the world, the sooner we establish a safe and effective cure, the better.

\section{Conflict of Interest}

None declared.

\section{References}

1 Coronavirus Disease (COVID-19) Situation Reports. Available at: https://www.who.int/emergencies/diseases/novel-coronavirus-2019/situation-reports. Accessed March 8, 2021

2 Abd El-Aziz TM, Stockand JD. Recent progress and challenges in drug development against COVID-19 coronavirus (SARS-CoV-2) - an update on the status. Infect Genet Evol 2020;83:104327

3 McKee DL, Sternberg A, Stange U, Laufer S, Naujokat C. Candidate drugs against SARS-CoV-2 and COVID-19. Pharmacol Res 2020;157:104859

4 "Solidarity" clinical trial for COVID-19 treatments. Available at: https://www.who.int/emergencies/diseases/novel-coronavirus-2019/global-research-on-novel-coronavirus-2019-ncov/ 
solidarity-clinical-trial-for-covid-19-treatments. Accessed March 8, 2021

5 Uzunova K, Filipova E, Pavlova V, Vekov T. Insights into antiviral mechanisms of remdesivir, lopinavir/ritonavir and chloroquine/hydroxychloroquine affecting the new SARS-CoV-2. Biomed Pharmacother 2020;131:110668

6 Tobaiqy M, Qashqary M, Al-Dahery S, et al. Therapeutic management of patients with COVID-19: a systematic review. Infect Prev Pract 2020;2(3):100061

7 Thiagarajan K. Covid-19: India is at centre of global vaccine manufacturing, but opacity threatens public trust. BMJ 2021;372(196):n196

8 Li L, Zhang W, Hu Y, et al. Effect of convalescent plasma therapy on time to clinical improvement in patients with severe and life-threatening COVID-19: a randomized clinical trial. JAMA 2020;324(5):460-470

9 Chen L, Xiong J, Bao L, Shi Y. Convalescent plasma as a potential therapy for COVID-19. Lancet Infect Dis 2020;20(4):398-400

10 Abolghasemi H, Eshghi P, Cheraghali AM, et al. Clinical efficacy of convalescent plasma for treatment of COVID-19 infections: Results of a multicenter clinical study. Transfus Apheresis Sci 2020;59(5):102875

11 Klasse PJ. Neutralization of virus infectivity by antibodies: old problems in new perspectives. Adv Biol 2014;2014:157895

12 Coughlin MM, Prabhakar BS. Neutralizing human monoclonal antibodies to severe acute respiratory syndrome coronavirus: target, mechanism of action, and therapeutic potential. Rev Med Virol 2012;22(1):2-17

13 Marano G, Vaglio S, Pupella S, et al. Convalescent plasma: new evidence for an old therapeutic tool? Blood Transfus 2016;14(2):152-157

14 Zhao Q He Y. Challenges of convalescent plasma therapy on COVID-19. J Clin Virol 2020;127:104358

15 Rojas M, Rodríguez Y, Monsalve DM, et al. Convalescent plasma in Covid-19: Possible mechanisms of action. Autoimmun Rev 2020;19(7):102554

16 Shamim S, Khan M, Kharaba ZJ, Ijaz M, Murtaza G. Potential strategies for combating COVID-19. Arch Virol 2020;165(11):2419-2438

17 Piyush R, Rajarshi K, Khan R, Ray S. Convalescent plasma therapy: a promising coronavirus disease 2019 treatment strategy. Open Biol 2020;10(9):200174

18 Wooding DJ, Bach H. Treatment of COVID-19 with convalescent plasma: lessons from past coronavirus outbreaks. Clin Microbiol Infect 2020;26(10):1436-1446

19 Liu L, Wei Q Lin Q et al. Anti-spike IgG causes severe acute lung injury by skewing macrophage responses during acute SARS-CoV infection. JCI Insight 2019;4(4):123158

20 Iqbal $\mathrm{H}$. The importance of cell-mediated immunity in COVID-19 - An opinion. Med Hypotheses 2020;143:110152

21 Selvi V. Convalescent plasma: a challenging tool to treat COVID-19 Patients-A lesson from the past and new perspectives. BioMed Res Int 2020;2020:2606058

22 Wong VWS, Dai D, Wu AKL, Sung JJ. Treatment of severe acute respiratory syndrome with convalescent plasma. Hong Kong Med J 2003;9(3):199-201

23 Simșek Yavuz S, Ünal S. Antiviral treatment of COVID-19. Turk J Med Sci 2020;50(SI-1):611-619

24 Poutanen SM, Low DE, Henry B, et al. National Microbiology Laboratory, Canada; Canadian Severe Acute Respiratory Syndrome Study Team. Identification of severe acute respiratory syndrome in Canada. N Engl J Med 2003;348(20):1995-2005

25 The PREVENT Study Group. Reduction of respiratory syncytial virus hospitalization among premature infants and infants with bronchopulmonary dysplasia using respiratory syncytial virus immune globulin prophylaxis. Pediatrics 1997;99(1):93-99
26 Leider JP, Brunker PAR, Ness PM. Convalescent transfusion for pandemic influenza: preparing blood banks for a new plasma product? Transfusion 2010;50(6):1384-1398

27 Rosenke K, Bounds CE, Hanley PW, et al. Human polyclonal antibodies produced by transchromosomal cattle provide partial protection against lethal Zaire Ebolavirus challenge in Rhesus macaques. J Infect Dis 2018;218(suppl_5) :S658-S661

28 Duan K, Liu B, Li C, et al. Effectiveness of convalescent plasma therapy in severe COVID-19 patients. Proc Natl Acad Sci U S A 2020;117(17):9490-9496

29 Verma HK, Farran B, Bhaskar LVKS. Convalescent plasma transfusion a promising therapy for coronavirus diseases 2019 (COVID-19): current updates. Antib Ther 2020;3(2):115-125

30 Christ GJ, Saul JM, Furth ME, Andersson K-E. The pharmacology of regenerative medicine. Pharmacol Rev 2013;65(3):1091-1133

31 Dzobo K, Thomford NE, Senthebane DA, et al. Advances in regenerative medicine and tissue engineering: innovation and transformation of medicine. Stem Cells Int 2018;2018:2495848

32 Chen F-M, Liu X. Advancing biomaterials of human origin for tissue engineering. Prog Polym Sci 2016;53:86-168

33 Christ B, Franquesa M, Najimi M, van der Laan LJW, Dahlke MH. Cellular and molecular mechanisms of mesenchymal stem cell actions. Stem Cells Int 2017;2017:2489041

34 Foley L, Whitaker M. Concise review: cell therapies: the route to widespread adoption. Stem Cells Transl Med 2012;1(5):438-447

35 Abdelrazik H, Giordano E, Barbanti Brodano G, Griffoni C, De Falco E, Pelagalli A. Substantial overview on mesenchymal stem cell biological and physical properties as an opportunity in translational medicine. Int J Mol Sci 2019;20(21):E5386

36 Han Y, Li X, Zhang Y, Han Y, Chang F, Ding J. Mesenchymal stem cells for regenerative medicine. Cells 2019;8(8):E886

37 Green EM, Lee RT. Proteins and small molecules for cellular regenerative medicine. Physiol Rev 2013;93(1):311-325

38 Biehl JK, Russell B. Introduction to stem cell therapy. J Cardiovasc Nurs 2009;24(2):98-103, quiz 104-105

39 Okano H, Sipp D. New trends in cellular therapy. Development 2020;147(18):dev192567

40 Jeyaraman M, Ranjan R, Kumar R, et al. Cellular therapy: shafts of light emerging for COVID-19. Stem Cell Investig 2020;7:11

41 Jeyaraman M, John A, Koshy S, et al. Fostering mesenchymal stem cell therapy to halt cytokine storm in COVID-19. Biochim Biophys Acta Mol Basis Dis 2021;1867(2):166014

42 Yorukoglu AC, Kiter AE, Akkaya S, Satiroglu-Tufan NL, Tufan AC. A concise review on the use of mesenchymal stem cells in cell sheet-based tissue engineering with special emphasis on bone tissue regeneration. Stem Cells Int 2017;2017:2374161

43 Ullah I, Subbarao RB, Rho GJ. Human mesenchymal stem cells - current trends and future prospective. Biosci Rep 2015;35(2):e00191

44 Volarevic V, Markovic BS, Gazdic M, et al.Ethical and safety issues of stem cell-based therapy. Int J Med Sci 2018;15(1):36-45

45 Pittenger MF, Discher DE, Péault BM, Phinney DG, Hare JM, Caplan AI. Mesenchymal stem cell perspective: cell biology to clinical progress. NPJ Regen Med 2019;4(1):22

46 Wei X, Yang X, Han ZP, Qu FF, Shao L, Shi YF. Mesenchymal stem cells: a new trend for cell therapy. Acta Pharmacol $\operatorname{Sin} 2013 ; 34(6): 747-754$

47 Berebichez-Fridman R, Montero-Olvera PR. Sources and clinical applications of mesenchymal stem cells: state-of-the-art review. Sultan Qaboos Univ Med J 2018;18(3):e264-e277

48 Kangari P, Talaei-Khozani T, Razeghian-Jahromi I, Razmkhah M. Mesenchymal stem cells: amazing remedies for bone and cartilage defects. Stem Cell Res Ther 2020;11(1):49

49 Paul D, Samuel SM, Maulik N. Mesenchymal stem cell: present challenges and prospective cellular cardiomyoplasty 
approaches for myocardial regeneration. Antioxid Redox Signal 2009;11(8):1841-1855

50 Gianakos AL, Sun L, Patel JN, Adams DM, Liporace FA. Clinical application of concentrated bone marrow aspirate in orthopaedics: A systematic review. World J Orthop 2017;8(6):491-506

51 Zhao Q, Ren H, Han Z. Mesenchymal stem cells: immunomodulatory capability and clinical potential in immune diseases. J Cell Immunother 2016;2(1):3-20

52 Bora P, Majumdar AS. Adipose tissue-derived stromal vascular fraction in regenerative medicine: a brief review on biology and translation. Stem Cell Res Ther 2017;8(1):145

53 Gentile P, Scioli MG, Bielli A, Orlandi A, Cervelli V. Comparing different nanofat procedures on scars: role of the stromal vascular fraction and its clinical implications. Regen Med 2017;12(8):939-952

54 Alexander RW. Understanding adipose-derived stromal vascular fraction (AD-SVF) cell biology and use on the basis of cellular, chemical, structural and paracrine components: a concise review. Journal of Prolotherapy 2012;4:e855-e869

55 Mazini L, Rochette L, Amine M, Malka G. Regenerative capacity of adipose derived stem cells (ADSCs), comparison with mesenchymal stem cells (MSCs) Int J Mol Sci 2019;20(10):E2523

56 Chu D-T, Nguyen Thi Phuong T, Tien NLB, et al. Adipose tissue stem cells for therapy: an update on the progress of isolation, culture, storage, and clinical application. J Clin Med 2019;8(7):E917

57 Atluri S, Manchikanti L, Hirsch JA. Expanded umbilical cord mesenchymal stem cells (UC-MSCs) as a therapeutic strategy in managing critically ill COVID-19 patients: the case for compassionate use. Pain Physician 2020;23(2):E71-E83

58 Marmotti A, Mattia S, Castoldi F, et al. Allogeneic umbilical cord-derived mesenchymal stem cells as a potential source for cartilage and bone regeneration: an in vitro study. Stem Cells Int 2017;2017:1732094

59 Rady D, Abbass MM, El-Rashidy AA, et al. Mesenchymal stem/progenitor cells: the prospect of human clinical translation. Stem Cells Int 2020;2020:8837654

60 Parekkadan B, Milwid JM. Mesenchymal stem cells as therapeutics. Annu Rev Biomed Eng 2010;12:87-117

61 Weiss ARR, Dahlke MH. Immunomodulation by mesenchymal stem cells (MSCs): mechanisms of action of living, apoptotic, and dead MSCs. Front Immunol 2019;10:1191

62 Abdi R, Fiorina P, Adra CN, Atkinson M, Sayegh MH. Immunomodulation by mesenchymal stem cells: a potential therapeutic strategy for type 1 diabetes. Diabetes 2008;57(7):1759-1767

63 Kyurkchiev D, Bochev I, Ivanova-Todorova E, et al. Secretion of immunoregulatory cytokines by mesenchymal stem cells. World J Stem Cells 2014;6(5):552-570

64 Machado Cde V, Telles PD, Nascimento IL. Immunological characteristics of mesenchymal stem cells. Rev Bras Hematol Hemoter 2013;35(1):62-67

65 Lee JW, Fang X, Krasnodembskaya A, Howard JP, Matthay MA. Concise review: Mesenchymal stem cells for acute lung injury: role of paracrine soluble factors. Stem Cells 2011;29(6):913-919

66 Lu Z, Chang W, Meng S, et al. Mesenchymal stem cells induce dendritic cell immune tolerance via paracrine hepatocyte growth factor to alleviate acute lung injury. Stem Cell Res Ther 2019;10(1):372

67 Alcayaga-Miranda F, Cuenca J, Khoury M. Antimicrobial activity of mesenchymal stem cells: current status and new perspectives of antimicrobial peptide-based therapies. Front Immunol 2017;8:339

68 Yagi H, Chen AF, Hirsch D, et al. Antimicrobial activity of mesenchymal stem cells against Staphylococcus aureus. Stem Cell Res Ther 2020;11(1):293
69 Sutton MT, Fletcher D, Ghosh SK, et al. Antimicrobial properties of mesenchymal stem cells: therapeutic potential for cystic fibrosis infection, and treatment. Stem Cells Int 2016;2016:5303048

70 Shah VK, Firmal P, Alam A, Ganguly D, Chattopadhyay S. Overview of immune response during SARS-CoV-2 Infection: lessons from the past. Front Immunol 2020;11:1949

71 Crivelli B, Chlapanidas T, Perteghella S, et al. Italian Mesenchymal Stem Cell Group (GISM). Mesenchymal stem/stromal cell extracellular vesicles: from active principle to next generation drug delivery system. J Control Release 2017;262:104-117

72 Gupta A, Kashte S, Gupta M, Rodriguez HC, Gautam SS, Kadam S. Mesenchymal stem cells and exosome therapy for COVID-19: current status and future perspective. Hum Cell 2020;33(4):907-918

73 Rezakhani L, Kelishadrokhi AF, Soleimanizadeh A, Rahmati S Mesenchymal stem cell (MSC)-derived exosomes as a cell-free therapy for patients infected with COVID-19: real opportunities and range of promises. Chem Phys Lipids 2021;234:105009

74 Pinky, Gupta S, Krishnakumar V, Sharma Y, Dinda AK, Mohanty S. Mesenchymal stem cell derived exosomes: a nano platform for therapeutics and drug delivery in combating COVID-19. Stem Cell Rev Rep 2021;17(1):33-43

75 Zhou P, Yang X-L, Wang X-G, et al. A pneumonia outbreak associated with a new coronavirus of probable bat origin. Nature 2020;579(7798):270-273

76 Grein J, Ohmagari N, Shin D, et al. Compassionate use of remdesivir for patients with severe Covid-19. N Engl J Med 2020;382(24):2327-2336

77 Ma N, Gai H, Mei J, et al. Bone marrow mesenchymal stem cells can differentiate into type II alveolar epithelial cells in vitro. Cell Biol Int 2011;35(12):1261-1266

78 Lanzoni G, Linetsky E, Correa D, et al. Umbilical cord mesenchymal stem cells for COVID-19 acute respiratory distress syndrome: A double-blind, phase $1 / 2 \mathrm{a}$, randomized controlled trial. Stem Cells Transl Med 2021;10(5):660-673

79 Tzouvelekis A, Paspaliaris V, Koliakos G, et al. A prospective, non-randomized, no placebo-controlled, phase Ib clinical trial to study the safety of the adipose derived stromal cells-stromal vascular fraction in idiopathic pulmonary fibrosis. J Transl Med 2013;11:171

80 Cardenes N, Aranda-Valderrama P, Carney JP, et al. Cell therapy for ARDS: efficacy of endobronchial versus intravenous administration and biodistribution of MAPCs in a large animal model. BMJ Open Respir Res 2019;6(1):e000308

81 Antoniou KM, Karagiannis K, Tsitoura E, et al. Clinical applications of mesenchymal stem cells in chronic lung diseases. Biomed Rep 2018;8(4):314-318

82 Cheng S-L, Lin C-H, Yao C-L. Mesenchymal stem cell administration in patients with chronic obstructive pulmonary disease: state of the science. Stem Cells Int 2017;2017:8916570

83 Hoffmann M, Kleine-Weber H, Schroeder S, et al. SARS-CoV-2 cell entry depends on ACE2 and TMPRSS2 and is blocked by a clinically proven protease inhibitor. Cell 2020;181(2): 271-280.e8

84 Wruck W, Adjaye J. SARS-CoV-2 receptor ACE2 is co-expressed with genes related to transmembrane serine proteases, viral entry, immunity and cellular stress. Sci Rep 2020;10(1):21415

85 Hamming I, Timens W, Bulthuis MLC. Lely AT, Navis G, van Goor H. Tissue distribution of ACE2 protein, the functional receptor for SARS coronavirus. A first step in understanding SARS pathogenesis. J Pathol 2004;203(2):631-637

86 Song P, Li W, Xie J, Hou Y, You C. Cytokine storm induced by SARS-CoV-2. Clin Chim Acta 2020;509:280-287

87 Al-Khawaga S, Abdelalim EM. Potential application of mesenchymal stem cells and their exosomes in lung injury: an 
emerging therapeutic option for COVID-19 patients. Stem Cell Res Ther 2020;11(1):437

88 Durand N, Mallea J, Zubair AC. Insights into the use of mesenchymal stem cells in COVID-19 mediated acute respiratory failure. NPJ Regen Med 2020;5(1):17

89 Raza SS, Khan MA. Mesenchymal stem cells: A new front emerge in COVID19 treatment. Cytotherapy 2020. Doi: 10.1016/j.jcyt.2020.07.002

90 Advanced Search - ClinicalTrials.gov. Available at: https://clinicaltrials.gov/ct2/search/advanced. Accessed March 9, 2021

91 Leng Z, Zhu R, Hou W, et al. Transplantation of ACE2- mesenchymal stem cells improves the outcome of patients with COVID-19 pneumonia. Aging Dis 2020;11(2):216-228

92 Liang B, Chen J, Li T, et al. Clinical remission of a critically ill COVID-19 patient treated by human umbilical cord mesenchymal stem cells: a case report. Medicine (Baltimore) 2020;99(31):e21429

93 Lukomska B, Stanaszek L, Zuba-Surma E, Legosz P, Sarzynska S, Drela K. Challenges and controversies in human mesenchymal stem cell therapy. Stem Cells Int 2019;2019:9628536

94 Ikebe C, Suzuki K. Mesenchymal stem cells for regenerative therapy: optimization of cell preparation protocols. BioMed Res Int 2014;2014:951512

95 Torre ML, Lucarelli E, Guidi S, et al. Gruppo Italiano Staminali Mesenchimali (GISM). Ex vivo expanded mesenchymal stromal cell minimal quality requirements for clinical application. Stem Cells Dev 2015;24(6):677-685

96 Codinach M, Blanco M, Ortega I, et al. Design and validation of a consistent and reproducible manufacture process for the production of clinical-grade bone marrow-derived multipotent mesenchymal stromal cells. Cytotherapy 2016;18(9):1197-1208

97 Grisendi G, Annerén C, Cafarelli L, et al.GMP-manufactured density gradient media for optimized mesenchymal stromal/stem cell isolation and expansion. Cytotherapy 2010;12(4):466-477
98 Wuchter P, Bieback K, Schrezenmeier H, et al. Standardization of Good Manufacturing Practice-compliant production of bone marrow-derived human mesenchymal stromal cells for immunotherapeutic applications. Cytotherapy 2015;17(2):128-139

99 Deasy BM, Anderson JE, Zelina S. Regulatory issues in the therapeutic use of stem cells. Regen Med Tissue Eng 2013. Doi: $10.5772 / 55945$

100 Peng H, Gong T, Huang X, et al. A synergistic role of convalescent plasma and mesenchymal stem cells in the treatment of severely ill COVID-19 patients: a clinical case report. Stem Cell Res Ther 2020;11(1):291

101 Kavianpour M, Saleh M, Verdi J. The role of mesenchymal stromal cells in immune modulation of COVID-19: focus on cytokine storm. Stem Cell Res Ther 2020;11(1):404

102 Fan X-L, Zhang Y, Li X, Fu Q-L. Mechanisms underlying the protective effects of mesenchymal stem cell-based therapy. Cell Mol Life Sci 2020;77(14):2771-2794

103 Naji A, Favier B, Deschaseaux F, Rouas-Freiss N, Eitoku M, Suganuma N. Mesenchymal stem/stromal cell function in modulating cell death. Stem Cell Res Ther 2019;10(1):56

104 Weiss DJ, English K, Krasnodembskaya A, Isaza-Correa JM, Hawthorne IJ, Mahon BP. The necrobiology of mesenchymal stromal cells affects therapeutic efficacy. Front Immunol 2019;10:1228

105 Robbins JB, Schneerson R, Szu SC. Perspective: hypothesis: serum IgG antibody is sufficient to confer protection against infectious diseases by inactivating the inoculum. J Infect Dis 1995;171(6):1387-1398

106 Casadevall A, Pirofski LA. Antibody-mediated regulation of cellular immunity and the inflammatory response. Trends Immunol 2003;24(9):474-478

107 Casadevall A,ScharffMD.Serum therapy revisited: animal models of infection and development of passive antibody therapy. Antimicrob Agents Chemother 1994;38(8):1695-1702 